University of Pennsylvania Carey Law School

Penn Law: Legal Scholarship Repository

Faculty Scholarship at Penn Law

3-28-2007

\title{
The Non-Problem of Free Will in Forensic Psychiatry and Psychology
}

Stephen J. Morse

University of Pennsylvania Carey Law School

Follow this and additional works at: https://scholarship.law.upenn.edu/faculty_scholarship

Part of the Criminal Law Commons, Jurisprudence Commons, Law and Psychology Commons, Philosophy of Mind Commons, Psychiatry Commons, and the Public Law and Legal Theory Commons

\section{Repository Citation}

Morse, Stephen J., "The Non-Problem of Free Will in Forensic Psychiatry and Psychology" (2007). Faculty Scholarship at Penn Law. 151.

https://scholarship.law.upenn.edu/faculty_scholarship/151

This Article is brought to you for free and open access by Penn Law: Legal Scholarship Repository. It has been accepted for inclusion in Faculty Scholarship at Penn Law by an authorized administrator of Penn Law: Legal Scholarship Repository. For more information, please contact PennlawIR@law.upenn.edu. 


\title{
The Non-Problem of Free Will in Forensic Psychiatry and Psychology
}

\author{
Stephen J. Morse, J.D., Ph.D.*
}

This article demonstrates that there is no free will problem in forensic psychiatry by showing that free will or its lack is not a criterion for any legal doctrine and it is not an underlying general foundation for legal responsibility doctrines and practices. There is a genuine metaphysical free will problem, but the article explains why it is not relevant to forensic practice. Forensic practitioners are urged to avoid all usage of free will in their forensic thinking and work product because it is irrelevant and spawns confusion. Copyright (C) 2007 John Wiley \& Sons, Ltd.

There is a problem about free will, but not in forensic psychiatry and psychology. The genuine problem of free will is metaphysical and often spawns confusion. ${ }^{1}$ Roughly, it refers to whether human beings possess the ability or power to act uncaused by anything other than themselves, which is referred to as libertarian freedom of the will. ${ }^{2}$ The importance of having this power or ability results from the controversial belief that it underwrites the possibility of holding people genuinely responsible. Solving the free will problem would have profound implications for responsibility doctrines and practices, but, at present, the problem plays no proper role in forensic practice or theory because this ability or its lack is not a criterion of any civil or criminal law doctrine.

Forensic psychiatry and psychology address problems genuinely related to responsibility, including consciousness, the formation of mental states such as intention and knowledge, the capacity for rationality, and compulsion, but they never address the presence or absence of free will. People sometimes use "free will" loosely to refer to genuine responsibility doctrines, but this simply distracts attention

\footnotetext{
*Correspondence to: Stephen J. Morse, J.D., Ph.D., University of Pennsylvania, 3400 Chestnut Street, Philadelphia, PA 19104-6204, U.S.A. E-mail: smorse@law.upenn.edu

${ }^{1}$ Specialists in the philosophy of free will and responsibility often distinguish between freedom of action, the freedom to do as one chooses, and freedom of the will, the freedom to choose what one would prefer to choose. This article will subsume both under the locution "freedom of the will" or "free will".

${ }^{2}$ This refers to freedom of the will and does not refer to libertarian politics. People who accept the possibility of libertarian free will may or may not adopt libertarian politics.
} 
from the real issues and perpetuates confusion. The only practical free will problem is the confusion among forensic practitioners and others who think that free will is a problem or who speak and write as if it is.

This article begins by drawing a distinction between an internal and external critique of a set of doctrines and practices such as mental health laws. It then demonstrates that the positive criteria for general legal responsibility, for mental health law in general, and for criminal responsibility in particular, do not include free will, and that lack of free will is not an excusing condition in current law.

The article next turns to the general metaphysical free will problem. This part argues that one potential solution to the free will problem, incompatibilist hard determinism, generates only an external critique of responsibility that is unrelated to forensic practice and that would obliterate the possibility of responsibility altogether. It also suggests that the other solution, compatibilism, provides a secure foundation for current practice and renders it immune to the potentially devastating challenge of the external critique. In other words, and despite common assertion to the contrary, libertarian free will is not even a necessary underlying foundation for the law's responsibility doctrines and practices.

The article then canvasses the persistent confusions about free will and responsibility that have bedeviled legal writing and forensic practice for decades. A brief, tongue-in-cheek section addresses the criteria and cure for Free Will Confusion Syndrome (FWCS). The article concludes by suggesting that forensic practitioners should forswear all use of free will conceptualizations and language.

\section{INTERNAL VERSUS EXTERNAL CRITIQUES}

If one is considering the relation of any variable to an institution, practice, or set of doctrines, the variable may be used to mount either an internal or an external critique. An internal critique accepts that the practice or doctrine is coherent and uses the other variable to explain or to reform the practice or doctrine. An external critique uses the other variable to demonstrate that the practice or doctrine is incoherent tout court. For example, forensic practitioners may wish to consider the relation of free will to criminal responsibility doctrines and practices. I shall use this example for ease of exposition, but the point is generalizable to any area of forensic interest, such as various competencies or forms of civil and quasi-criminal commitment.

An internal argument accepts that criminal responsibility is a coherent concept and uses free will to explain the positive rules and practices we have or to criticize these rules and practices normatively for the purpose of improving them. An external argument uses free will to demonstrate that the concept of criminal responsibility is incoherent or unjustifiable and therefore it should be abandoned. Thus, any practitioner or commentator who accepts that at least some people who commit crimes are responsible and may justifiably be punished are necessarily making an internal argument, at least implicitly, because the justifiability of responsibility is assumed. 


\section{A POSITIVE ACCOUNT OF RESPONSIBILITY}

If a business person makes a bad deal because she is inattentive to crucial information, the contract will be enforced; if she is inattentive because she is crazy, she may be able to avoid the contract. An ex-con with three priors for aggravated assault who threatens to do it again cannot be incarcerated unless she gets close enough to completion to qualify for criminal attempt liability; if she threatens to commit the same crime because she is crazy, she may be involuntarily civilly committed. An agent who carelessly makes an unreasonable mistake about the need to use deadly force in self-defense will be convicted of murder or manslaughter; a delusional agent who makes a delusional mistake about the need to use deadly force to save her own life may be acquitted by reason of insanity.

Why does the law treat some crazy people specially and what are the criteria the law uses to determine whether an agent should be treated specially? To understand the answers to these questions, we must first address the law's view of the person and the law's view of responsibility generally. After answering these questions in the abstract, I will turn to the justification and criteria for mental health law in general and then to criminal responsibility as a specific example.

\section{The Legal View of the Person}

The law's view of the person is a creature capable of practical reason, an agent who forms and acts on intentions that are the product of the person's desires and beliefs. The law does not treat persons generally as non-intentional creatures or mechanical forces of nature. It could not be otherwise. Laws could not guide people ex ante and ex post unless people were the types of creature who could use laws as premises in their practical reasoning. The law's model of the person fully fits people with mental disorders, including the most severe disorders. They, too, have desires and beliefs and form intentions and act based on them. Their reasons for action may be affected by distorted sensory experiences and beliefs, for example, but they do act for reasons. Indeed, it is crucial to remember that, with few and controversial exceptions, people with mental disorders are intentional agents and not just mechanisms.

\section{The General Legal Criteria for Responsibility and Excuse}

The law's concept of responsibility follows logically from the nature of law itself and its concept of the person. As a system of rules that guides and governs human interaction, law tells citizens what they may and may not do, what they must or must not do, what abilities are required competently to perform certain tasks, and what consequences will follow from their conduct. Unless human beings were rational creatures who could understand the good reasons for action, including the relevant facts and rules, and could conform to legal requirements through intentional action, the law would be powerless to affect human action. Legally responsible agents are therefore people who have the general capacity to grasp and be guided by good 
reason in particular legal contexts. ${ }^{3}$ For example, they must be generally capable of properly using the rules as premises in practical reasoning. The usual legal presumption is that most adults are so capable.

Note that the law's requirement is possession of a general capacity at the time in question rather than whether it is in fact exercised on that occasion. Acting irrationally, rationally and foolishly are common, even among people with the greatest capacity for rational conduct. Failure to exercise a capacity does not necessarily mean that one lacks that capacity. For the law, if the person is capable of exercising the capacity for rationality if there is good reason to do so - as there always is when important interests are at stake - then the person may be held responsible, even if he or she failed to exercise that capacity.

The law's requirement for responsibility of a general capacity for rationality is not self-defining. It must be understood according to some contingent, normative notion both of rationality and of how much capability is required. For example, legal responsibility might require the capability of understanding the reason for an applicable rule, as well as the rule's narrow behavior command and the consequence for failure to comply. These are matters of moral, political, and, ultimately, legal judgment, about which reasonable people can and do differ. There is no uncontroversial definition of rationality or of what kind and how much is required for responsibility in various legal contexts. These are normative issues and, whatever the outcome might be within a polity and its legal system, the debate is about human action - intentional behavior potentially guided by reasons.

Now let us turn to the law's excusing conditions, those situations in which the agent will not be held responsible and may be treated specially. If the general capacity for rationality is the primary responsibility condition, then lack of that capacity is the primary excusing condition. It explains, for example, why young children, some people with dementia, and some people with mental disorder are not held responsible, at least in some contexts. Again, how much lack of capacity is necessary to find the agent not responsible is a normative moral, social, political, and ultimately legal issue. It is not a medical, psychological, or psychiatric issue.

Compulsion or coercion is also an excusing condition, but it is less well understood than lack of rational capacity. ${ }^{4}$ It is useful first to distinguish cases of literal and metaphorical compulsion. Literal compulsion exists when the person's bodily movement is a pure mechanism, the product of mechanistic causes and not rationalizable by the agent's desires, beliefs, and intentions. For example, if a much stronger person pulls my arm and literally forces it against the head of a third person despite my best efforts not to move my arm, the movement of my arm is not my act at all. It is not a product of my intention. For another example, a neuromuscular tremor produced by a neurological disorder is not my action because it is not intentional. Again, the movement of my arm is pure mechanism.

In contrast, metaphorical compulsion exists when the agent acts intentionally, but in response to some hard choice imposed on the agent through no fault of his or her own. In cases of metaphorical compulsion, it is useful to distinguish two party and

\footnotetext{
${ }^{3}$ I borrow the felicitous concept of being able to grasp and be guided by reason from Jay Wallace. R. JAY WALLACE, RESPONSIBILITY AND THE MORAL SENTIMENTS (1994).

${ }^{4}$ See Stephen J. Morse, Uncontrollable Urges and Irrational People, 88 VA. L. REV. 1025 (2002) (addressing the difficulty with compulsion excuses and suggesting that most cases seeming to require such an excuse are better understood in terms of irrationality).
} 
one party cases. The former occurs when another person threatens an agent by placing him or her in a "do-it-or-else" situation. For example, if a miscreant holds a gun to your head and threatens to kill you unless you kill another innocent person, it would be wrong to kill the innocent other. But if you do kill, the killing conduct is fully intentional and a perfectly rational response to the desire to live and the belief that one would otherwise be killed oneself. Although it would be wrong to kill under these circumstances, we may decide as a metaphorical and normative matter that the act should be excused because the agent was compelled by a threat that was simply too hard for most citizens to resist.

One party or internal compulsion cases are more difficult to understand. Recognize, first, that if the internally compelled agent is irrational, there is no need for an independent compulsion excuse. Only in cases in which the agent is seemingly rational do we need to consider compulsion. The cases that most fit this category are "disorders of desire," such as addictions, paraphilias, compulsive gambling, pyromania, and the like. Note again, however, that when the addict seeks and uses substances, when the pedophile molests a child, when the compulsive gambler places a bet, and when the pyromaniac sets a fire, the agent is acting. She acts intentionally to satisfy her craving for the purpose of achieving relief, of obtaining pleasure, or of both. In these cases, if the person frequently yields to her strong desires at great social, occupational, or legal cost to herself, the agent will often say that she could not help herself, that she was not in control. Consequently, we may again say that metaphorically and normatively she was compelled and should be excused.

Note that none of the law's general criteria for responsibility or excuse refer to free will or its absence. Lack of action, lack of rationality, and compulsion all excuse, but none of these conditions has anything to do with free will. There may be problems conceptualizing and evaluating the lack of rational capacity or compulsion. These are real problems for law and for forensic psychiatry and psychology, but they are not free will problems. Lawyers and forensic practitioners often speak and write as if these are "free will" problems, as if lack of free will were a synonym for lack of action, irrationality, or compulsion. Nevertheless, free will is doing no work whatsoever independent of these genuine excusing conditions and it thus threatens to confuse the issues.

\section{The Justification of and the Criteria for Mental Health Laws}

Now let us apply the foregoing account of legal responsibility and excuse to mental heath law generally. Then we will apply it to criminal responsibility in particular.

Mental health laws are justified because at least some people with mental disorder are not responsible in some legal contexts and thus the state may apply special rules to them. ${ }^{5}$ The state does not regulate mental disorder per se because mental disorder alone does not provide sufficient justification to intervene in a citizen's life. Nor does the state intervene with special mental health rules, if behavior the state has an interest in regulating is produced by factors other than mental abnormality. For

\footnotetext{
${ }^{5}$ There may be a few limited exceptions to the general justification of non-responsibility, e.g. Washingtonv. Harper, 494 U.S. 210 (1990) (holding that a state can involuntarily treat a prison inmate with psychotropic medication, if it is medically indicated and necessary to maintain prison safety and security), but, arguably, these exceptions are not properly mental health laws because they would apply if the same problem of danger arose from a purely physical disorder. In any case, such potential exceptions "prove the rule".
} 
example, a criminal defendant who did not know what he was doing because he was simply careless or inattentive will not be found legally insane. For another example, the potential for future violent conduct alone, no matter how severe and predictively certain, does not per se justify preventive state intervention. ${ }^{6}$ The state may intervene with special mental health rules only if the citizen is not responsible for his or her legally relevant behavior. In such cases, the usual presumptions in favor of liberty and autonomy are suspended because responsible agency is the premise for these presumptions. The criteria for non-responsibility may of course vary from context to context. For example, one must be less responsible to avoid criminal conviction for a sex offense than to avoid commitment as a mentally abnormal sexually violent predator. ${ }^{7}$ These are matters of public policy, but non-responsibility is crucial.

To satisfy the non-responsibility justification that underlies mental health laws, all include three criteria: a mental abnormality, legally relevant behavior (or potentially legally relevant behavior), and a causal relationship between the legally relevant behavior and mental disorder. ${ }^{8}$

For the law's purposes, mental abnormality may be defined in ways that do not precisely track or employ standard psychiatric and psychological definitions. For example, for the purpose of upholding the constitutionality of a mentally abnormal sexually violent predator commitment, the United States Supreme Court accepted as constitutional the following definition of "mental abnormality":

congenital or acquired condition affecting the emotional or volitional capacity which predisposes the person to commit sexually violent offenses in a degree constituting such person a menace to the health and safety of others. ${ }^{9}$

In addition to not being standard, this definition is also circular and empty, but it nonetheless passed constitutional muster. In practice, however, most mental health law doctrines do not contain non-standard definitions and traditional diagnoses will be employed. A statute or judicial decision may limit, however, which diagnoses or clinical conditions will satisfy the threshold criterion of a mental abnormality. For example, the federal insanity defense standard requires that the defendant must have been suffering from a "severe mental disease or defect." 10

Legally relevant behavior refers to the type of conduct the state desires to regulate, such as criminal responsibility attributions and potentially violent conduct. For a familiar example, under the M'Naghten test, in addition to suffering from a sufficient mental disorder, a legally insane defendant must not have known the nature and quality of his act or must not have known that the act was wrong. It is the presence or absence of such knowledge, not whether the defendant suffered from a mental disorder per se, that is legally relevant for a responsibility attribution. A mentally ill citizen will be civilly committable only if he is also dangerous. Potential violent conduct, not mental disorder per se, is the legally relevant behavior that concerns the state.

\footnotetext{
${ }^{6}$ Again, there are a few exceptions, but they are very exceptional and strictly limited. See, e.g., U.S. $v$. Salerno, 481 U.S. 739 (1987) (upholding pretrial detention and denial of bail for particularly dangerous defendants, but noting that the detention is non-punitive and strictly limited by the speedy trial right). ${ }^{7}$ Kansas v. Hendricks, 521 U.S. 346 (1997).

${ }^{8}$ See Stephen J. Morse, Crazy Behavior, Morals and Science: An Analysis of Mental Health Law, 51 S. CAL. L. REV. 527 (1978).

${ }^{9}$ Kansas v. Hendricks, note 7 supra (citing Kansas Stat. Ann. Sec. 59-29a02 (b) (1994)).

${ }^{10} 18$ U.S.C. Sec. 17 (a).
} 
The third criterion - the causal relation between mental abnormality and the legally relevant behavior - is critical to the justification of mental health laws because it is the doctrinal expression of the non-responsibility foundation that permits some crazy people to be treated specially. It is also the most complicated of the three criteria and often creates confusion. The question is how best to interpret this causal requirement.

It is crucial to recognize that the causal criterion does not mean that the legally relevant behavior is simply the product, in a mechanical, but-for sense, of the mental disorder. Rather, it means most fundamentally that the mental disorder undermined the agent's capacity for rationality in the context in question or, much less frequently, that it placed the agent in a perceived hard choice situation. Moreover, the agent is not responsible for the undermining of his or her rational capacity because the agent is not responsible for suffering from a mental disorder. The law does not treat people as non-intentional creatures or mechanical forces of nature. The law treats persons, including people with mental disorders, as intentional creatures, agents who form intentions based on their desires and beliefs. Mental health laws treat crazy people specially not because the behaviors of crazy people are mechanisms, but because people with mental disorder may lack sufficient rational capacity in the context at issue. In other words, they were or are not responsible for their legally relevant conduct.

To see clearly that causation in part by mental disorder does not per se mitigate or excuse responsibility, imagine cases in which mental disorder undeniably plays a causal role in legally relevant behavior but does not undermine rational capacity and therefore does not undermine responsibility. For example, a clinically hypomanic burglar who would not have engaged in the criminal behavior but for the heightened sense of energy, acuity and confidence his rising mood produced will have no excuse for his burglary. A person suffering from paranoid personality disorder who would not have joined a militant organization and engaged in its criminal program but for suffering from the disorder will have no excuse for the crimes he commits in support of the organization.

In sum, mental health laws treat some people with mental disorder specially because these people are not capable of being guided by reason in the legal context in question. To return to the examples used at the beginning of this section, the crazy business person may be allowed to avoid her contract if her mental disorder sufficiently prevented her from rationally understanding the nature of the deal she made. A person whose potentially dangerous conduct is motivated by irrational beliefs or perceptions may be involuntarily civilly committed if she lacks sufficient rational capacity to be responsible for her potential violence. A criminal defendant whose crime was motivated by a delusional belief may be found not guilty by reason of insanity if the delusion rendered the defendant sufficiently unable to know what he was doing or to know right from wrong. At base, virtually all mental health laws are rationality tests applicable in particular contexts.

In this entire account of mental health law generally, there has not been the slightest mention of free will or its absence. Lack of free will is not a mental health law criterion. Indeed, it is irrelevant to the actual practice of mental health law and therefore irrelevant to the practice of forensic psychiatry and psychology in this context. Many people, including judges and practicing lawyers, believe that lack of free will is what justifies application of mental health laws generally and in specific cases, but they are wrong. As noted, free will talk is often used synonymously with 
the positive criteria of mental health law, but doing so risks and perpetuates the confusion mental health law criteria with the genuine free will problem. To explore further the error of believing that there is a genuine and independent free will problem in our positive law and in the practice of forensic psychiatry and psychology, let us turn specifically to criminal responsibility, which is the forensic context in which talk of free will is probably most common (and most distracting).

\section{Criminal Responsibility}

As a matter of current, positive law, an agent will be prima facie criminally responsible if the agent acts intentionally and with the appropriate mental state, the mens rea, required by the definition of the offense, such as purpose, knowledge, recklessness, or negligence. Criminal law typically defines an act as an intentional bodily movement performed by an agent whose consciousness is reasonably intact. Mental states have their ordinary language, common sense meanings. No degree of commitment or rationality is included in the definitions of mens rea. An act committed ambivalently for irrational reasons is considered intentional if it was done on purpose. Even if the agent is fully prima facie responsible, however, the agent ultimately may still not be criminally responsible if an excusing condition, an affirmative defense, such as legal insanity (essentially a rationality defect) or duress (a compelling "hard choice" situation, such as a "do-it-or-else" threat at gunpoint), was present when the agent committed the offense. Although one might quibble about details and there is substantial variation across the states, this account accurately reflects the law's current, core conception of criminal responsibility. ${ }^{11}$

The logic of the foregoing account is that a defendant who wants to avoid imputation of criminal responsibility must create reasonable doubt about whether he or she acted intentionally, consciously and with the required mens rea, or the defendant must establish an affirmative defense. ${ }^{12}$ If the agent does not act at all because the bodily movement was not intentional or the agent's consciousness was substantially compromised, the agent is not prima facie responsible. For example, a reflex or behavior in an altered state of consciousness, such as sleepwalking, will not be considered the defendant's action, even if the defendant's bodily movements caused a harm. An agent who does not act is acquitted outright. Similarly, if the agent lacks a requisite mental state, the agent is also not prima facie criminally responsible and must be acquitted outright of the crime requiring that mental state. For example, suppose a defendant shoots at an object he actually believes to be a tree, but it turns

\footnotetext{
${ }^{11}$ I have been teaching criminal law in law schools for over three decades. Trust me: I'm a law professor. But if you do not, any good treatise will bear out this claim. See, e.g., JOSHUA DRESSLER, UNDERSTANDING CRIMINAL LAW, 4TH ED. (2006).

${ }^{12}$ I use the locution "establish an affirmative defense" because the United States Supreme Court has made it clear that a jurisdiction may shift the burden of persuasion to the defendant for affirmative defenses. See Leland v. Oregon, 343 U.S. 790 (1952) (permitting shifting the persuasion burden for legal insanity to the defendant); Rivera v. Delaware, 429 U.S. 877 (1976) (the same); Dixon v. United States, 126 U.S. 2437 (2006) (permitting shifting the persuasion burden for duress to the defendant). Many jurisdictions have taken advantage. For example, in federal insanity defense cases, the defendant must prove that he or she was legally insane by clear and convincing evidence. Of course, a jurisdiction can also place the burden of persuasion on the prosecution. In practice, wherever the burden of persuasion is placed for affirmative defenses, the defendant will have the burden of producing sufficient evidence to warrant the defense.
} 
out to be a person who is killed. The shooting was intentional action but the defendant cannot be convicted of intentional homicide because he did not intend to kill a human being. If he or she was sufficiently careless, however, the defendant might be convicted of negligent homicide, defined as killing in a situation in which a reasonable person should recognize that his or her conduct created a substantial and unjustifiable risk of death.

Like the definitions of crimes, affirmative defenses also have specific criteria. Consider first the insanity defense, using the Model Penal Code test as an example. ${ }^{13}$ To be found legally insane, at the time of the crime the defendant must have been suffering from a mental disorder and, as a result, lacked substantial capacity to appreciate the criminality of his action or to conform his action to the requirement of the law. Thus, if the defendant is not sufficiently disordered to meet the law's definition of mental disorder, or did not lack the requisite substantial capacity, a legal insanity defense will fail. Now consider the Model Penal Code standard for the affirmative defense of duress. ${ }^{14}$ Duress is established if the defendant is threatened with death or grievous bodily harm unless he harms another and a person of reasonable firmness would have yielded in this situation. The defense will fail if the threat was not of death or grievous bodily harm, say a threat to destroy only the defendant's valued property, or if a person of reasonable firmness would not have yielded, say killing five people to save one's own life.

To establish prima facie guilt or to defeat an affirmative defense, the prosecution need not prove that the defendant had free will. To defeat the prosecution's prima facie case, the defendant must negate the elements of conscious, intentional action and mens rea; to establish an affirmative defense, the defense must introduce sufficient evidence of the criteria for the defense. To avoid criminal responsibility either by negating the prosecution's prima facie case or by establishing an affirmative defense, the defendant need not demonstrate that he or she lacked free will. People will often say that a defendant who acted under duress or who was legally insane lacked free will. In such cases, however, free will is simply a confusing and conclusory way of saying that the legal criteria for excuse were met. Lack of free will independent of the behavioral legal criteria for excuse does no work whatsoever in explaining why such a defendant is excused.

For a final confirmation of the thesis that free will plays no role in the positive criteria for criminal responsibility, consider the United States Supreme Court's recent decision, Clark v. Arizona, in which the Supreme Court had one of its rare opportunities to clarify the relation between mens rea and insanity. ${ }^{15}$ The questions presented were whether Arizona's unusually narrow insanity defense test, which asked only whether the defendant could distinguish between right and wrong, violated substantive due process rights and whether an Arizona rule that excluded virtually all expert evidence concerning mental disorder offered for the purpose of negating mens rea violated procedural due process. Although legal insanity and the presence of mens rea are probably the criminal law issues to which free will is allegedly most relevant, and although there was extensive discussion of the history of legal insanity and of the role of mens rea, the Court did not so much as mention free will to

\footnotetext{
${ }^{13}$ MODEL PENAL CODE, Sec. 4.01(1).

${ }^{14}$ Id., Sec. 2.09(1).

${ }^{15} 126$ S. Ct. 2709 (2006).
} 
decide the issues. There were many problems with the Court's analysis, especially of the mens rea issue, ${ }^{16}$ but failure to discuss free will was not among them.

In short, free will or lack of it is not a criterion for criminal responsibility or non-responsibility. Once again, it is irrelevant to the actual practice of criminal law and, by extension, to the actual practice of forensic psychiatry and psychology that aids criminal justice legal actors and decision makers. It is true that people, including judges, practicing lawyers and a few law professors, talk as if free will were important in criminal law, but this is clearly wrong as a matter of positive law. They sometimes mean, however, that free will is a necessary foundational justification for responsibility, even if it is not a criterion in any legal doctrine. The next section, which discusses the metaphysical free will problem, demonstrates that this assumption is not necessary to justify responsibility doctrines and practices according to an entirely plausible and practical resolution of the metaphysical free will problem.

\section{THE GENUINE FREE WILL PROBLEM}

Free will is usually taken to mean, explicitly by philosophers and implicitly by others, that the agent has the ability to cause his or her own behavior uncaused by anything else. In a phrase, the buck stops entirely with the agent. This ability is sometimes called contra-causal freedom, agent origination, metaphysical libertarianism, and other like phrases. Only a small number of philosophers adhere to this view, which has been termed a "panicky" metaphysics ${ }^{17}$ because it is so implausible. ${ }^{18}$ Many people believe, however, that libertarianism is a foundational assumption for law. Thus, if it is false, then many legal doctrines and practices, especially those relating to responsibility, may be entirely incoherent. But, as we shall see, metaphysical libertarianism is not a necessary support for current responsibility doctrines and practices.

Most philosophers and, I speculate, virtually all forensic psychiatrists and psychologists, believe that the universe is deterministic or universally caused, or nearly so, especially above the sub-atomic level. There is no uncontroversial definition of determinism and we will never be able to confirm that it is true or not. As a working definition, however, let us assume, roughly, that all events have causes that operate according to the physical laws of the universe and that were themselves caused by those same laws operating on prior states of the universe in a continuous thread of causation going back to the first state. Even if this is too strong, the universe seems so sufficiently regular and lawful that rationality demands that we must adopt the hypothesis that universal causation is approximately correct. ${ }^{19}$

It is important to understand that, for the determinist, biological causes pose no more or less challenge to responsibility than non-biological or social causes. As a conceptual and empirical matter, we do not necessarily have more control over

\footnotetext{
${ }^{16}$ See Stephen J. Morse \& Morris B. Hoffman, The Uneasy Entente Between Insanity and Mens Rea: Clark v. Arizona (ms under submission, 2006).

${ }^{17}$ P. F. Strawson, Freedom and Resentment, in FREE WILL 59, 80 (G. Watson ed., 1982).

${ }^{18}$ HILARY BOK, FREEDOM AND RESPONSIBILITY 42-51 (1998).

${ }^{19}$ Galen Strawson, Consciousness, Free Will, and the Unimportance of Determinism, 32 INQUIRY 3 (1989) (terming this hypothesis the "realism constraint").
} 
psychological or social causal variables than over biological causal variables. More important, in a world of universal causation or determinism, causal mechanisms are indistinguishable in this respect and biological causation creates no greater threat to our life hopes than psychological or social causation. ${ }^{20}$ For purposes of the metaphysical free will debate, a cause is just a cause, whether it is biological, psychological, sociological, or astrological.

If determinism is true, the people we are and the actions we perform have been caused by a chain of causation over which we mostly had no rational control and for which we could not possibly be responsible. We do not have contra-causal freedom. How can responsibility be possible for action or for anything else in such a universe? How can it be rational and fair for civil and criminal law to hold anyone accountable for anything, including blaming and punishing people because they allegedly deserve it? Those who believe that responsibility is not compatible with determinism are called "incompatibilists" and adopt different conclusions depending on their view of determinism. "Libertarian" incompatibilists believe that determinism is not true for most action because we have metaphysical libertarian freedom and that, therefore, we are responsible. "Hard determinist" incompatibilists believe that determinism is true, deny that we have contra-causal freedom, and conclude that responsibility is impossible. ${ }^{21}$ "Compatibilists" believe that determinism is true, deny that contra-causal freedom is necessary for responsibility, and hold that responsibility is possible under the right conditions.

No analysis of this problem could conceivably persuade everyone. There are no decisive, analytically incontrovertible arguments to resolve the metaphysical question of the relation between determinism, libertarian free will and responsibility. Moeover, the question is metaphysical, not scientific. Indeed, the debate is so fraught that even theorists who adopt the same general approach to the metaphysical challenge substantially disagree. Nevertheless, the view one adopts has profound consequences for legal (and moral) theory and practice.

\section{Incompatibilism}

Incompatibilism does not try either to explain or to justify our responsibility concepts and practices. It simply assumes that genuine responsibility is metaphysically unjustified. For example, a central incompatibilist argument is that people can be responsible only if they could have acted otherwise than they did, but if determinism is true, they could not have acted other than they did. ${ }^{22}$ Consequently, the incompatibilist claims that even if an internally coherent account of responsibility

\footnotetext{
${ }^{20}$ See JANET RADCLIFFE RICHARDS, HUMAN NATURE AFTER DARWIN: A PHILOSOPHICAL INTRODUCTION (2000) (complete analysis of the indistinguishability of biological and social causation as threats to personhood and ordinary responsibility).

${ }^{21} \mathrm{I}$ have already rejected libertarianism as empirically implausible, so the rest of the discussion will focus only on the hard determinist form of incompatibilism, which is a coherent position held by many. Later in this part I discuss why libertarianism is not a necessary foundation for our positive responsibility practices. ${ }^{22}$ This is sometimes called the "principle of alternate possibilities". It has generated endless disputes between incompatibilists, who believe it is flatly inconsistent with responsibility, and compatibilists, who believe that it is not inconsistent with responsibility. See Wallace, note 3 supra at 115-117, 251-265.
} 
and related practices can be given, it will be a superficial basis for responsibility, which is only an illusion. ${ }^{23}$

Incompatibilism thus provides an external critique of responsibility. To see why, remember that causal determinism "goes all the way down." It applies to all people, to all events. Thus, if determinism is true and is genuinely inconsistent with responsibility, then no one can ever be really responsible for anything and responsibility attributions cannot properly justify further action. But western theories of morality and the law do hold some people responsible and excuse others, and the law responds accordingly. And when we do excuse, it is not because there has been a little local determinism at work. For example, young children are not considered fully responsible because they are incapable of recognizing and of properly weighing the right reasons for action and forbearance, not because they are determined creatures but adults are not. Determinism does not loosen its grip on us as we age.

If the incompatibilists are right, forensic psychiatrists, forensic psychologists, and everyone else have a massive and genuine free will problem because all mental health laws depend on the non-responsibility assumption, which in turn assumes that most people are responsible, that responsibility is the default condition. If no one is responsible, forensic practitioners have nothing to contribute to decision making about responsibility because there is nothing to decide. Indeed, if much of legal doctrine and practice is erected on a metaphysically libertarian foundation, much of law (and morality) may be incoherent ab initio. Thus, if determinism is true and libertarianism is necessary for responsibility, determinism creates an all-encompassing external critique of law in general and mental health law in particular. The question, then, is whether as rational agents we must swallow our pride, accept incompatibilism because it is so self-evidently true, and somehow transform the legal system accordingly.

\section{Compatibilism}

Compatibilists, who agree with incompatibilists that determinism is true, have three basic answers to the incompatibilist challenge. First, they claim that responsibility attribution and related practices are human activities constructed by us for good reason and that they need not conform to any ultimate metaphysical facts about genuine or "ultimate" responsibility. Indeed, some compatibilists deny that conforming to ultimate metaphysical facts is even a coherent goal in this context. Second, compatibilism holds that our positive doctrines of responsibility are fully consistent with determinism. Third, compatibilists believe that our responsibility doctrines and practices are normatively desirable and consistent with moral, legal, and political theories that we firmly embrace. The first claim is theoretical; the third is primarily normative. There are very powerful arguments for the first and third claims. ${ }^{24}$ For the purpose of this article, however, which is

\footnotetext{
$\overline{{ }^{23} \text { See SAUL SMILANSKY, FREE WILL AND ILLUSION 40-73, 145-219 (2000) (arguing that free }}$ will is an illusion, but an illusion that is indispensable).

${ }^{24}$ See Stephen J. Morse, Reason, Results and Criminal Responsibility, 2004 U. ILL. L. REV. 363, 437-444.
} 
addressed to whether forensic practice has a free will problem, the second claim is the most important.

Let us begin with the most general responsibility and excusing conditions. Recall that the capacity for rationality is the primary responsibility criterion and its lack is the primary excusing condition. Now, it is simply a fact about human beings that they have different capacities for rationality in general and in specific contexts. Once again, for example, young children in general have less rational capacity than adults. It is also true that rationality differences differentially affect agents' capacity to grasp and to be guided by good reason. Differences in rational capacity and its effects are real even if determinism is true. Compulsion is also an excusing condition, but it is simply another fact about human beings that some people act in response to external or internal hard choice threats to which persons of reasonable firmness might yield and most people most of the time are not in such situations when they act. This is true even if determinism is true and even if people could not have acted otherwise.

For a specific example, consider again the doctrines of criminal responsibility. Assume that the defendant has caused a prohibited harm. Prima facie responsibility requires that the defendant's behavior was action and performed with a requisite mental state. Now it is simply true that some bodily movements are intentional and performed in a state of reasonably integrated consciousness and some are not. It is also true that some defendants possess the requisite mental state and some do not. The truth of determinism does not mean that actions are indistinguishable from non-actions or that mental states do not exist. These facts are true and make a perfectly rational legal difference even if determinism is true. Determinism is fully consistent with prima facie guilt and innocence.

Now consider the defenses of insanity and duress. Some people with mental disorder do not know right from wrong; others do. In cases of potential duress, some people face a hard choice that a person of reasonable firmness would yield to and most people do not. Once again, these differences make perfect sense according to dominant retributive and consequential theories of punishment. A causal account can explain how these variations were caused to occur, but it does not mean that they do not exist. Determinism is fully consistent with both the presence and absence of affirmative defenses. In sum, the legal criteria used to identify which defendants are criminally responsible map onto real behavioral differences that justify differential legal responses.

A causal determinist account would become inconsistent with our responsibility practices only if our scientific investigations convinced us that we are not the types of creature the law takes us to be-conscious and intentional creatures who act for reasons. ${ }^{25}$ If it is true, for example, that we are all automata, then no one is acting and no one can be responsible for action. ${ }^{26}$ Unlike the claimed inconsistency between determinism and responsibility, which is a metaphysical question, this critique is empirical and in principle capable of resolution. The conclusion that we are essentially automata would once again provide an external critique of responsibility

\footnotetext{
${ }^{25}$ See section "A positive account of responsibility", subsection "The legal view of the person", supra.

${ }^{26} \mathrm{I}$ have termed this the "no action thesis". Stephen J. Morse, Inevitable Mens Rea, 27 HARVARD J. L. \& PUB. POL. 51 (2003).
} 
and leave no room for forensic practice to aid decision making concerning mental health law's core justification of non-responsibility.

Although some scientists are gesturing in this direction, ${ }^{27}$ there is little in current psychology or neuroscience that suggests that most people most of the time are not conscious and intentional creatures who act for reasons. The folk psychological theory of personhood that the law implicitly adopts seems secure. As the eminent philosopher of mind, Jerry Fodor, has written

\footnotetext{
... if commonsense intentional psychology were really to collapse, that would be, beyond comparison, the greatest intellectual catastrophe in the history of our species; if we're that wrong about the mind, then that's the wrongest we've ever been about anything. The collapse of the supernatural, for example, doesn't compare ... Nothing except, perhaps, our commonsense physics ... comes as near our cognitive core as intentional explanation does. We'll be in deep, deep trouble if we have to give it up .... But be of good cheer; everything is going to be all right. ${ }^{28}$
}

In sum, even if determinism is true, forensic psychiatry and psychology have no practical free will problem because the doctrines of responsibility are entirely consistent with the truth of determinism or because responsibility is impossible tout court. Libertarianism is not necessary to underwrite our positive conceptions of responsibility. Because compatibilism is consistent with our responsibility practices and their centrality and because there is no convincing theoretical reason to reject it, all participants in the legal system, including forensic psychiatrists and psychologists, have good reason to embrace compatibilism. Forensic practitioners can comfortably continue to play a crucial role in helping legal decision makers assess responsibility in all civil and criminal law contexts without being distracted by the irrelevant issue of free will.

\section{PERSISTENT CONFUSIONS: THE FUNDAMENTAL PSYCHOLEGAL ERROR}

The most persistent confusion about our actual doctrines and practices concerning responsibility, which I have termed the "fundamental psycholegal error", 29 is the mistaken belief that causation, especially by an abnormal cause, is per se an excusing condition. In brief, this error relies on the same argument the incompatibilist makes without recognizing that it provides an external critique that must deny the possibility of any responsibility. If the truth of determinism or universal causation is an excusing condition, it applies not just in any particular legal context, such as capital punishment proceedings. It applies everywhere and always.

In a causally deterministic universe, all phenomena, including human actions, are fully caused. If causation were per se an excusing condition, no one could ever be responsible for anything. Thus, causation can not be an excusing condition in law

\footnotetext{
${ }^{27}$ See DANIEL WEGNER, THE ILLUSION OF CONSCIOUS WILL (2002).

${ }^{28}$ JERRY FODOR, PSYCHOSEMANTICS: THE PROBLEM OF MEANING IN THE PHILOSOPHY OF MIND xii (1987).

${ }^{29}$ Stephen J. Morse, Culpability and Control, 142 U. PENN. L. REV. 1587, 1592-94 (1994).
} 
and morals, both of which hold some people responsible and excuse others. Although this is a simple and straightforward analytical point, the error persists. ${ }^{30}$

For purposes of assessing responsibility, it does not matter whether the cause of the behavior in question is biological, psychological, sociological, or some combination of the three. Adducing a genetic or neurophysiological cause does no more work than adducing an environmental cause. The question is always whether the legal criterion for non-responsibility in question is met, however that condition may have been caused. A person who is mentally disordered and does not know right from wrong will be excused from criminal responsibility whether her rationality impairment was primarily a product of faulty genetics, a neurotransmitter defect, bad parenting, social stress, the alignment of the planets, or some combination of the above. The most important question for forensic practice is whether the legal excusing condition was present, not how it was caused. At most, causal knowledge, if sufficiently precise, may help establish whether, or the likelihood that, the legal criterion in question was satisfied.

For example, in the recent case of Roper $v$. Simmons, ${ }^{31}$ advocates for abolition of the death penalty for adolescents who committed capital murder when they were 16 or 17 years old argued that the demonstrated lack of complete myelination of the cortical neurons of the adolescent brain was reason to believe that 16 and 17 year old murderers were insufficiently responsible to deserve capital punishment. The Roper briefs were filled with discussion of new neuroscientific evidence that confirms that adolescent brains are different from adult brains in ways that are consistent with the observed behavioral, rational capacity differences between adolescents and adults arising from differences in impulsivity, susceptibility to peer influence, and susceptibility to stress. But it is the latter behavioral differences that alone bear on culpability and responsibility. Assuming the validity of the neuroscientific evidence, what does it add? The rigorous behavioral studies already confirm the behavioral differences. No one thinks that these data are invalid because adolescent subjects in the research studies were faking or for some other reason. The moral and constitutional implications of the data may be controversial, but the data are not. At most, the neuroscientific evidence provides a partial causal explanation of why the observed behavioral differences exist and thus some further evidence of the validity of the behavioral differences. It is only of limited and indirect relevance to responsibility assessment, which is based on behavioral criteria concerning rationality. Diminished responsibility follows from diminished rationality, however the latter is caused.

Abnormal causation, say, by mental disorder, also does not excuse per se, but excuses only if it produces a genuine excusing condition, such as lack of capacity to appreciate the criminality of one's actions. As forensic practitioners know, a person suffering from mental disorder that plays a causal role in the sufferer's behavior may nonetheless retain sufficient capacity for rationality to be held fully responsible. To return to an example used earlier, a clinically hypomanic robber or hypomanic

\footnotetext{
${ }^{30}$ See, e.g., Committee on Addictions of the Group for the Advancement of Psychiatry, Responsibility and Choice in Addiction, 53 PSYCHIATRIC SERVICES 707, 708 (2002) (pointing to genetic and biological variables responsible for addiction and suggesting that partial determinism or partial causation provides a partial excuse); Anders Kaye, Resurrecting the Causal Theory of the Excuses, 83 NEBRASKA L. REV. 1116 (2005). My critics complain that I repeat this argument frequently. I plead guilty as charged and will continue to recidivate as long as people continue to manifest this confusion.

${ }^{31} 125$ S. Ct. 1183 (2005).
} 
business person may be especially energetic, mentally acute, and confident when the agent mugs or makes a contract. Indeed, but for the clinical condition they would not have mugged or made the deal, but there is no question about the agent's criminal responsibility or competence to contract in this case.

Causation is also not the equivalent of compulsion, even if mental disorder is part of the causal chain. All behaviors are caused, but not all behavior is the product of the hard choices that meet moral and legal criteria for compulsion. If causation were the equivalent of compulsion, everyone would always be compelled and excused. Moreover, unless mental disorder produces an internal hard choice for the agent, it also is not per se compelling. A delusional belief or a hallucination may produce irrational reasons for action, but irrational reasons are not per se more compelling than rational reasons. For example, a person who delusionally believes in the need to use deadly self-defense is no more compelled to act than a non-delusional agent with the same honest belief. The former, like M'Naghten himself, may be excused because he is irrational, but compulsion plays no role in such cases.

Finally, it follows logically that if full causation is not per se an excusing condition then "partial causation" also does not partially or fully excuse the agent. Most of the time we possess only imperfect, partial understanding of the causes of behavior. It is important to remember, however, that not possessing knowledge of the complete causal account of a person's behavior does not mean that a complete causal account does not exist. Indeed, the notion that only some phenomena are caused or determined, but others are not, is incoherent. If this is a universally caused or deterministic universe, all phenomena are caused, whether or not we have knowledge of those causes.

In any case, discovering a partial normal or abnormal cause for behavior does not partially or completely excuse the agent unless this cause produces a genuine excusing condition. For example, various causes we discover may in part explain why an agent's rationality is fully or partially impaired, but then it is the impairment of rationality, not causation, that is doing the excusing work. By the same token, discovering part of the causation of behavior does not mean that the behavior was compelled to that degree. Causation is not per se compulsion and "partial causation" is not per se partial or complete compulsion.

As examples of these confusions and how to avoid them, consider the attempt to use alleged new syndromes or clinical conditions as criminal law excuses. Again, it does not matter if the cause of the condition seems primarily biological, such as Frontal Lobe Dysfunction (FLD), or psychological, such as Battered Victim Syndrome. Assume for the purpose of argument that the syndrome has been validated and that in an individual case the causal connection between the syndrome and the crime can be established in a common sense manner. In other words, assume that the agent's mental disorder affected her practical reason, motivating her criminal behavior.

If new syndrome sufferers are to be excused, it will not be because they did not have free will when they committed their crimes. As we have seen, lack of free will is not a legal excusing condition and it is not a criterion for any diagnostic entity. Moreover, there is no reason whatsoever to create a "new" excuse for any of these conditions because causation by the condition, even if the condition plays a very powerful causal role in explaining the behavior, is not per se an excusing condition. The syndrome or condition will play an excusing role only if it deprives the sufferer 
of the capacity for rationality sufficiently to meet the requirements for legal insanity or some form of mitigation. However, then again, the excusing work is being done by impaired rationality, not by the presence of the syndrome. And if the syndrome does not sufficiently impair the defendant's capacity for rationality, it will have no excusing force whatsoever, no matter how much of a causal role it played. Also, causation in part by the syndrome does not mean that the criminal behavior was compelled. To say that a syndrome caused a crime tells us nothing about whether the defendant deserves excuse or mitigation (except in New Hampshire, which still retains the misguided, conceptually confused "product" test for legal insanity ${ }^{32}$ ).

\section{FREE WILL CONFUSION SYNDROME (FWCS) AND ITS CURE}

The only "free will problem" in forensic psychiatry and psychology (and law) is that many practitioners suffer from FWCS, a cognitive disorder that is most generally marked by the erroneous belief that free will is a specific or foundational criterion for responsibility in morality and law. As we have seen, it is not. It will be useful, however, to identify the tentative diagnostic criteria for this disorder. This diagnostic entity is being announced for the first time in this article and thus it needs substantial further investigation. I am confident, however, that most of the following signs and symptoms will be included in the final criteria.

1. Believing that science can solve the free will problem.

2. Believing that psychiatry or psychology have any data to contribute to whether a particular person has free will.

3. Believing that free will or its lack is a legal criterion for responsibility and excuse.

4. Using "free will" as a premise or conclusion in a forensic argument. For example, "the defendant lacked free will and was therefore legally insane" or "the defendant lacked free will."

5. Believing or saying that causation excuses or mitigates responsibility.

6. Believing or saying that causation is the equivalent of compulsion.

Manifesting any one of the signs and symptoms is sufficient to make the diagnosis. The number of criteria manifested indicates the disorder's severity.

It is fortunate that the cure for FWCS is simple: Cognitive Jurotherapy (CJ). All the afflicted forensic practitioner needs is understanding of three things: What the free will problem really is; What are the genuine criteria for legal responsibility and excuse; Why free will and legal criteria are not related. In other words, a little reading should do the trick. Although the philosophical free will literature can be ferociously complex, ${ }^{33}$ the level of understanding necessary for the forensic practitioner and lawyer is not particularly demanding. Thus, a complete cure should be easily attainable with an inexpensive, non-invasive therapy that has no known side-effects.

\footnotetext{
${ }^{32}$ New Hampshire adopted this rule in the late 19th Century. State v. Fones, 50 N.H. 369 (1871).

${ }^{33}$ See, generally, ROBERT KANE, ED., THE OXFORD HANDBOOK OF FREE WILL (2002).
} 


\section{CONCLUSION}

There is no free will problem in forensic psychiatry and forensic psychology. It is as simple as that. The practical moral of our story is brief: Forensic psychiatrists and psychologists should avoid all mention of free will in their reports, testimony, and scholarship. They should not even think about free will as an issue in forensic work. Using the concept of free will can only confuse oneself and the legal agents to whom our work is addressed. It can never properly be a premise or conclusion in any forensic argument. It can never clarify any legal issue or help resolve any legal case.

If one has a taste for deep philosophical problems, free will is of course worth thinking about. The issue is an endlessly interesting evergreen that will never be solved to everyone's satisfaction. But if one thinks about the problem in this sense, one is doing philosophy, not forensic work. Some people think philosophy is a disease, however, so be forewarned.

\section{ACKNOWLEDGEMENTS}

I am grateful to my colleagues for their many helpful suggestions. I thank Joel Dvoskin. As always, I thank my personal attorney, Jean Avnet Morse, for her sound, sober counsel and moral support. 